\title{
Eradication of Helicobacter pylori in Children by Triple Therapy Regimens of Amoxicillin, Omeprazole, and Clarithromycin or Azithromycin
}

\author{
Mohammad Reza Esmaeili-Dooki, ${ }^{1}$ Hossein Shirdel, ${ }^{1, *}$ and Mahmood Hajiahmadi ${ }^{1}$ \\ ${ }^{1}$ Non-Communicable Pediatric Diseases Research Center, Amirkola Children's Hospital, Babol University of Medical Sciences, Babol, IR Iran \\ ${ }^{*}$ Corresponding author: Hossein Shirdel, Non-Communicable Pediatric Diseases Research Center, Amirkola Children's Hospital, Babol University of Medical Sciences, P. O. Box: \\ 4731741151, Babol, IR Iran. Tel: +98-1132346963, Fax:+98-1132346963, E-mail: dr.h.shirdel@gmail.com
}

Received 2015 May 19; Revised 2015 September 1; Accepted 2015 September 28

\begin{abstract}
Background and Objectives: The present study aimed to evaluate the effect of classical and azithromycin-containing triple therapy eradication regimen against $H$. Pylori in children, and to determine the level of patients' tolerance.

Patients and Methods: This single clinical trial was performed in 2014 on 2 to 15 years old children. All children, in whom H.Pylori infection was confirmed through multiple biopsies of the stomach and required treatment, were enrolled in the study. H. Pylori-positive patients were treated alternately with two different drug regimens; Group OCA received clarithromycin $7.5 \mathrm{mg} / \mathrm{kg} /$ day every 12 hours for 10 days, amoxicillin $50 \mathrm{mg} / \mathrm{kg} /$ day every 12 hours for 10 days, and omeprazole $1 \mathrm{mg} / \mathrm{kg} /$ day every 12 hours for two weeks, and Group OAA received azithromycin $10 \mathrm{mg} / \mathrm{kg} /$ day once a day (before meal) for 6 days along with amoxicillin and omeprazole. Four to six weeks after completion of treatment, patients' stool was tested for H. Pylori through the monoclonal method using the Helicobacter antigen quick kit.

Results: There were no significant differences between the two groups regarding gender and age of patients. Based on ITT analysis, the therapeutic response in the OAA and OCA groups were $56.2 \%$ and $62.5 \%$, respectively $(\mathrm{P}=0.40)$. Drug adverse effects were $15.6 \%$ in the OCA and $3.1 \%$ in the OAA group $(\mathrm{P}=0.19)$.

Conclusions: The therapeutic response was seen in more than half of the patients treated with triple therapy of $H$. Pylori eradication regimen including azithromycin or clarithromycin, and there was no significant difference between the two treatment groups.
\end{abstract}

Keywords: Treatment, Drug, GI Biopsy, Children, Helicobacter pylori

\section{Background}

Helicobacter pylori is a Gram-negative, spiral, catalasepositive, and urease-positive bacillus which contributes to a wide range of gastrointestinal (GI) and extra-GI diseases $(1,2)$. H. Pylori has gained particular importance nowadays since it has infected about $50 \%$ of the world's population. However, its prevalence is high in developing countries $(1,3-5)$. The most common routes of transmission of the infection are oral-oral, oral-digestive, and fecal-oral contacts $(6,7)$. The infection has no affinity toward a particular gender (8). This common pathogen can develop chronic gastroenteritis and increase the risk for peptic ulcer and gastric cancer. Infection often begins at an early age and reaches its maximum in adults. Although most cases are asymptomatic, dyspepsia is likely to occur. Moreover, extra-GI symptoms have been also reported. Therefore, treatment and eradication of the infection is important. According to the Conference of Maastricht III, the first line of treatment is amoxicillin, omeprazole, and clarithromycin for 7 days which results in an eradication rate of about $80 \%$ (75\% $98 \%$ ) (9-11). However, in addition to the $20 \%$ resistance of the bacteria to this regimen, cases of drug intolerance and the incidence of adverse events such as diarrhea, abdominal pain, nausea and vomiting, and taste intolerance have been reported. The second-line treatment is a quadruple regimen including metronidazole and bismuth, which is associated with a high incidence of side effects resulting in drug intolerance $(12,13)$.

Since azithromycin is a macrolide, it reaches a high concentration in the tissue and remains there for a few days after oral administration; therefore, it can be used in the eradication of $H$. Pylori (14-18). The eradication rate of azithromycin used in different regimens has been reported $60 \%$ to $80 \%$ (19). According to a meta-analysis, its effect is similar to classical regimen and it is better tolerated by patients (19).

\section{Objectives}

The present study aimed to evaluate the effect of classical and azithromycin-containing triple therapy eradication regimen against $H$. Pylori in children, and to de-

Copyright (C) 2015, Growth \& Development Research Center. This is an open-access article distributed under the terms of the Creative Commons Attribution-NonCommercial 4.0 International License (http://creativecommons.org/licenses/by-nc/4.0/) which permits copy and redistribute the material just in noncommercial usages, provided the original work is properly cited. 
termine the level of patients' tolerance and drug's side effects.

\section{Patients and Methods}

This single clinical trial was performed in 2014 on 2 to 15 years old children. Volume of the sample was estimated based on past studies $(20,21)$ with $95 \%$ confidence and 90\% statistical power. Patients were randomly allocated into two age-matched groups by table of random numbers. H. Pylori infection was confirmed through multiple biopsies of the stomach in all children with digestive problems (including dyspepsia, gastrointestinal bleeding, and chronic abdominal pain) that needed upper GI endoscopy. Biopsy samples were sent in $10 \%$ formalin solution to the laboratory for histological examination. Children with consumption of antibiotics in the last two months, allergy to the studied medicines, prior treatment for H. Pylori, chronic liver and kidney diseases, and simultaneous use of NSAIDs and other drugs were excluded from the study.

H. Pylori-positive patients were treated alternately with two different drug regimens: group 1 received clarithromycin $7.5 \mathrm{mg} / \mathrm{kg} /$ day every 12 hours for 10 days, amoxicillin $50 \mathrm{mg} / \mathrm{kg} /$ day every 12 hours for 10 days, and omeprazole 1 $\mathrm{mg} / \mathrm{kg} /$ day every 12 hours for two weeks. Group 2 received azithromycin $10 \mathrm{mg} / \mathrm{kg} /$ day once a day (before meal) for 6 days along with amoxicillin and omeprazole. Azithromycin syrup was provided from Tehran Shimi Co. and tablets from Kharazmi Company, Clarithromycin syrup from Chemidarou and tablets from Rouz Darou Companies, amoxicillin syrup from Farabi Company, and omeprazole capsules from Abidi Company, all in Tehran, Iran. The attending resident was blind to the drugs administered to patients. A questionnaire has been prepared on the basis of previous studies (19) that evaluated the drug's side effects and intolerance and was completed by the patients or their parents. Four to six weeks after completion of treatment, patients' stool was tested for H. Pylori with monoclonal method using the Helicobacter Antigen Quick Kit (Generic Assays GmbH, Germany) which has a sensitivity of $85 \%$ - $96 \%$ and specificity of $83 \%$ - 93\% (22-24). A positive result of this antigen in stool was defined as treatment failure. The study was approved by the ethics committee of the Babol university of medical sciences (clinical trial registration number IRCT2013112115475N1), and informed consent was obtained from the parents. The collected data were analyzed using SPSS-20 through comparison of recovery level and side effects between the two treatment methods with Chi-square test, Fisher's exact test, and t-test. The regimens were analyzed with the methods ITT (intention to treat) and PP (per protocol). Pvalues less than 0.05 were considered significant.

\section{Results}

The study was performed on two groups consisting of 32 members receiving either omeprazole-clarithromycinamoxicillin (OCA) or omeprazole-azithromycin-amoxicillin (OAA) regimens. The baseline characteristics of patients are depicted in Table 1 . As shown in the table, there were no significant differences between the two groups regarding gender distribution and mean age of the patients. Abdominal pain with and without nausea and vomiting was the most common cause of endoscopy in the two study groups. Endoscopic findings of the patients are shown in Table 1 . As can be seen, antral nodularity was the most common endoscopic finding in the patients.

\begin{tabular}{|c|c|c|c|}
\hline Group & OAA & OCA & P Value \\
\hline Gender & & & 0.31 \\
\hline Male & $18(56.2)$ & $13(40.6)$ & \\
\hline Female & $14(43.8)$ & $19(59.4)$ & \\
\hline Age & $7.9 \pm 3.4$ & $9.1 \pm 3.6$ & 0.17 \\
\hline Cause of endoscopy & & & 0.02 \\
\hline Abdominal pain & $19(59.4)$ & $23(71.9)$ & \\
\hline Abdominal pain + nausea + vomiting & $10(31.2)$ & $2(6.2)$ & \\
\hline Other & $3(9.4)$ & $7(21.9)$ & \\
\hline Endoscopy finding & & & 0.98 \\
\hline Antral nodularity & $18(56.3)$ & $9(59.4)$ & \\
\hline Erythematous & $7(21.9)$ & $6(18.8)$ & \\
\hline Antral nodularity + gastric erosion & $1(3.1)$ & $2(6.2)$ & \\
\hline Thickening & $1(3.1)$ & $1(3.1)$ & \\
\hline Duodenal ulcer & $3(9.4)$ & $2(6.2)$ & \\
\hline Gastric ulcer & $2(6.3)$ & $2(6.2)$ & \\
\hline
\end{tabular}

\footnotetext{
${ }^{\mathrm{a}}$ Data are presented as No. (\%) or (mean $\left.\pm \mathrm{SD}\right)$.
} 
The therapeutic response to the OCA and OAA regimens are depicted in Table 2. Based on ITT analysis, the therapeutic response in the OAA and OCA groups were 56.2\% and $62.5 \%$, respectively, with no statistically significant differences. Drug intolerance was 9.4\% in the OCA and 3.1\% in OAA group. Table 2 shows the adverse effects observed in the two treatment groups. As shown in the table, there was no significant difference between the two groups regarding the rate of side effects.

The therapeutic response in the two treatment groups in terms of gender is presented in Table 3. As can be seen, no significant difference was found between the two treatment groups in therapeutic response regarding gender.

Table 2. Therapeutic Response and Adverse Effects of Patients in Two Groups ${ }^{\mathrm{a}}$

\begin{tabular}{|c|c|c|c|}
\hline Therapeutic response & OAA & OCA & PValue \\
\hline ITT & & & 0.4 \\
\hline Positive tests & $13(40.6)$ & $9(28.1)$ & \\
\hline Negative tests & $18(56.2)$ & $20(62.5)$ & \\
\hline Drug intolerance & $1(3.1)$ & $3(9.4)$ & \\
\hline PP & & & 0.431 \\
\hline Positive tests & $13(38.1)$ & $9(31)$ & \\
\hline Negative tests & $18(61.9)$ & $20(69)$ & \\
\hline Drug intolerance & - & - & \\
\hline Adverse effects & & & 0.196 \\
\hline Yes & $1(3.1)$ & $5(15.6)$ & \\
\hline No & $31(96.9)$ & $27(84.4)$ & \\
\hline
\end{tabular}

Table 3. The Therapeutic Response of Patients in Two Groups According Sexes ${ }^{\mathrm{a}}$

\begin{tabular}{|c|c|c|c|}
\hline \multirow{2}{*}{ Patients Therapeutic Response } & \multicolumn{2}{|c|}{ Gender } & \multirow[t]{2}{*}{ P Value } \\
\hline & Female & Male & \\
\hline OAA & & & 0.198 \\
\hline Positive test & $8(57.1)$ & $5(27.8)$ & \\
\hline Negative test & $6(42.9)$ & $12(66.7)$ & \\
\hline Drug intolerance & - & $1(5.6)$ & \\
\hline OCA & & & 0.357 \\
\hline Positive test & $7(36.8)$ & $2(15.4)$ & \\
\hline Negative test & $10(52.6)$ & $10(76.9)$ & \\
\hline Drug intolerance & $2(10.5)$ & $1(7.7)$ & \\
\hline
\end{tabular}

\section{Discussion}

Eradication of H. Pylori with classic triple therapy in children may be associated with intolerance and complications from Clarithromycin. Its replacement with other macrolides (Azithromycin) with shorter treatment time and lower dose can reduce these side effects with the same eradication effect.

According to the results of ITT analysis, the therapeutic response was seen in $56.2 \%$ of the OAA group and $62.5 \%$ of the OCA group with no statistically significant difference between them. In other words, the therapeutic response was observed in more than half of the patients in both treatment groups. In a study conducted by Sarkeshikian et al. (25), 165 adult patients with symptoms of dyspepsia were divided into two groups; the first group (89 patients) was treated with omeprazole, amoxicillin, and azithromycin and the second group (76 patients) with amoxicillin, omeprazole, and clarithromycin. According to the breath test performed 6 weeks later; the eradication rate was $75 \%$ in the first group and $82 \%$ in the second group, and there was no statistically significant difference between the two groups (25). This study was consistent with our study regarding the lack of significant difference in the therapeutic response between the two groups. Although this study was conducted in adults, the therapeutic response in each group was individually higher than in the present study. In a study conducted in Virginia, USA, by Sullivan et al.(26), 56 adult patients with GI symptoms and with $H$. Pylori confirmed by endoscopy were enrolled in the study and divided into two groups of 27 patients (treated with bismuth, lansoprazole, amoxicillin, and clarithromycin), and 29 patients (treated with bismuth, lansoprazole, amoxicillin, and azithromycin). After 8 weeks of treatment, the patients were evaluated with urea breath test. The PP analysis results showed an eradication rate of $84.6 \%$ in the first group and $55.5 \%$ in the second group, with a statistically significant difference between them (26). Although this study was performed in adults, it had two other differences with the present study; first, the therapeutic response was higher; second, the therapeutic response observed in clarithromycin group was higher than in azithromycin group. In a study by Bahremand et al. (27) entitled "Evaluation of the effectiveness of triple and quadruple therapy regimens for eradication of Helicobacter pylori in children referred to Imam Khomeini Hospital, Tehran," patients with $H$. Pylori infection determined by histological examination were divided into two groups. The triple-drug regimen included amoxicillin (50 mg/kg/day), omeprazole (1 mg/ $\mathrm{kg} /$ day), clarithromycin (15 $\mathrm{mg} / \mathrm{kg} /$ day), and the quadruple regimen included omeprazole ( $1 \mathrm{mg} / \mathrm{kg} /$ day $)$, amoxicillin (50 mg/kg/day), metronidazole (20 mg/kg/day), and bismuth citrate ( $8 \mathrm{mg} / \mathrm{kg} /$ day) for 10 days. Patients were assessed by urea breath test 4 weeks after treatment, which showed eradication of $H$. Pylori in $92 \%$ of the triple therapy group and 84\% of the quadruple therapy group (27). The therapeutic response was also higher in this study compared with ours. The reason for the difference in results between the two studies may be related to the fact that previous study was done over a decade ago, so an increase in antimicrobial resistance over time may have decreased treatment success rate in our study. 
During 1995 - 1996 in Japan, Kato et al. (28) studied 22 patients of 8 to 16 years of age who had active lesions and confirmed H. Pylori infection. They had undergone eradication therapy in which 10 patients received double-drug regimen of omeprazole ( $1 \mathrm{mg} / \mathrm{kg}$ bid) and amoxicillin (30 $\mathrm{mg} / \mathrm{kg}$ bid), and 12 patients received triple-drug regimen of clarithromycin (15 mg/kg bid) along with omeprazole and amoxicillin for 14 days. No difference was found between these two treatment groups (28). Differences between results of the present study and other studies can be attributed to various factors, for example, this study was conducted in children, whereas most studies were performed in adults. Also, the important consideration in this context may be the increased bacterial resistance. Antimicrobial resistance and diversity of $H$. Pylori in children (29-34) are the key factors in the failure of anti- $H$. Pylori regimens $(35,36)$, which may be caused by indiscriminate and arbitrary use of antibiotics in Iran, especially Azithromycin, which is highly used for different infections including respiratory infections.

According to a meta-analysis, there is no ideal first or second-line treatment for achieving 100\% eradication. The therapeutic order should be carried out according to the initial treatment and local antimicrobial resistance studies. The common endoscopic finding was nodularity in antrum that had no effect on treatment response; the two groups did not differ in this respect. In agreement with ours, study of Rafeey et al. showed the most common finding was nodularity in antrum and there was no relationship between the genotypes of $H$. Pylori that is effective in the response to treatment, with endoscopic findings (37).

The results of this study showed that the rate of drug intolerance in the OCA and OAA groups was 9.4\% and 3.1\%, respectively, with no significant difference between them and no major adverse effects in either treatment groups. Minakari et al. in 2010 evaluated a quadruple therapy including azithromycin or clarithromycin as the secondline therapy. The rate of intolerance to the regimen was $3.5 \%$ in the azithromycin-receiving group and $4.3 \%$ in the clarithromycin-receiving group, and there was no significant difference between them (38). This is similar to the present study; however, compared to the present study, the rates of intolerance in both groups were lower in patients who received the second-line treatment.

This study showed that eradication of H. Pylori with classic triple therapy in children with complications of clarithromycin, can be used azithromycin as other macrolide with a shorter time.

Since the response rate was lower than ideal in both regimens, it is suggested to carry out studies with more patients and newer regimens, and to determine the rate of antimicrobial resistance in comparison with clarithromycin.

\section{Acknowledgments}

The authors would like to thank Mrs. Moslemi for secretarial assistance.

\section{References}

1. Suerbaum S, Michetti P. Helicobacter pylori infection. $N$ Engl J Med. 2002;347(15):1175-86. doi: 10.1056/NEJMra020542. [PubMed: 12374879]

2. Vale FF, Vitor JM. Transmission pathway of Helicobacter pylori: does food play a role in rural and urban areas? Int J Food Microbiol. 2010;138(1-2):1-12. doi: 10.1016/j.ijfoodmicro.2010.01.016 [PubMed: 20122750]

3. Torres J, Pérez-Pérez G, Goodman KJ, Atherton JC, Gold BD, Harris PR, et al. A Comprehensive Review of the Natural History of Helicobacter pylori Infection in Children. Arch Med Res. 2000;31(5):431-69. doi: 10.1016/s0188-4409(00)00099-0. [PubMed: 11179581]

4. Blanchard SS, Bauman L, Czinn SJ. Treatment of Helicobacter pylori in Pediatrics. Curr Treat Options Gastroenterol. 2004;7(5):40712. [PubMed: 15345211]

5. Jafar S, Jalil A, Soheila N, Sirous S. Prevalence of helicobacter pylori infection in children, a population-based cross-sectional study in west iran. Iran J Pediatr. 2013;23(1):13-8. [PubMed: 23550042]

6. Rodrigues MN, Queiroz DM, Bezerra Filho JG, Pontes LK, Rodrigues RT, Braga LL. Prevalence of Helicobacter pylori infection in children from an urban community in north-east Brazil and risk factors for infection. Eur J Gastroenterol Hepatol. 2004;16(2):201-5. [PubMed:15075995]

7. Raymond J, Bergeret M, Kalach N. [Helicobacter pylori infection in children]. Presse Med. 2008;37(3 Pt 2):513-8. doi: 10.1016/j. lpm.2007.07.028. [PubMed:18255252]

8. Levine TS, Price AB. Helicobacter pylori: enough to give anyone an ulcer! Br J Clin Pract. 1993;47(6):328-32. [PubMed: 8117558]

9. Malfertheiner P, Megraud F, O'Morain C, Bazzoli F, El-Omar E, Graham D, et al. Current concepts in the management of Helicobacter pylori infection: the Maastricht III Consensus Report Gut. 2007;56(6):772-81. doi: 10.1136/gut.2006.101634. [PubMed: 17170018]

10. Perri F, Qasim A, Marras L, O'Morain C. Treatment of Helicobacter pylori infection. Helicobacter. 2003;8 Suppl 1:53-60. [PubMed: 14617218]

11. Das JC, Paul N. Epidemiology and pathophysiology of Helicobacter pylori infection in children. Indian JPediatr. 2007;74(3):28790. doi: 10.1007/s12098-007-0046-6. [PubMed:17401270]

12. Sun WH, Ou XL, Cao DZ, Yu Q, Yu T, Hu JM, et al. Efficacy of omeprazole and amoxicillin with either clarithromycin or metronidazole on eradication of Helicobacter pylori in Chinese peptic ulcer patients. World J Gastroenterol. 2005;11(16):2477-81. [PubMed: 15832421]

13. Gisbert JP. Rescue Therapy for Helicobacter pylori Infection 2012. Gastroenterol Res Pract. 2012;2012:974594. doi 10.1155/2012/974594. [PubMed: 22536225]

14. Megraud F, Darmaillac V, Brügmann D. Helicobacter pylori and azithromycin. Pathologie-biologie. 1995;43(6):555-60. [PubMed: 8539082]

15. Silva FM, Eisig JN, Teixeira AC, Barbuti RC, Navarro-Rodriguez T, Mattar R. Short-term triple therapy with azithromycin for Helicobacter pylori eradication: low cost, high compliance, but low efficacy. BMC Gastroenterol. 2008;8:20. doi:10.1186/1471-230X-8-20. [PubMed: 18510773]

16. Caselli M, Trevisani L, Tursi A, Sartori S, Ruina M, Luzzi I, et al Short-term low-dose triple therapy with azithromycin, metronidazole and lansoprazole appears highly effective for the eradication of Helicobacter pylori. Eur J Gastroenterol Hepatol. 1997;9(1):45-8. [PubMed: 9031898]

17. Di Mario F, Dal Bo N, Grassi SA, Rugge M, Cassaro M, Donisi PM, et al. Azithromycin for the cure of Helicobacter pylori infection. Am J Gastroenterol.1996;91(2):264-7. [PubMed: 8607490]

18. Bertoni G, Sassatelli R, Nigrisoli E, Tansini P, Bianchi G, Della Casa G, et al. Triple therapy with azithromycin, omeprazole, and amoxicillin is highly effective in the eradication of Helicobacter pylori: a controlled trial versus omeprazole plus amoxicillin. Am J Gastroenterol.1996;91(2):258-63. [PubMed: 8607489]

19. Dong J, Yu XF, Zou J. Azithromycin-containing versus standard triple therapy for Helicobacter pylori eradication: a metaanalysis. World J Gastroenterol. 2009;15(48):6102-10. [PubMed 


\section{5]}

20. Najafi M, Sobhani M, Khodadad A, Farahmand F, Motamed F. Reinfection Rate after Successful Helicobacter pylori Eradication in Children. Iran J Pediatr. 2010;20(1):58-62. [PubMed: 23056683]

21. Ahmad K, Fatemeh F, Mehri N, Maryam S. Probiotics for the treatment of pediatric helicobacter pylori infection: a randomized double blind clinical trial. Iran J Pediatr. 2013;23(1):79-84. [PubMed: 23446685]

22. Iranikhah A, Ghadir MR, Sarkeshikian S, Saneian H, Heiari A, Mahvari M. Stool antigen tests for the detection of Helicobacter pylori in children. Iran J Pediatr. 2013;23(2):138-42. [PubMed: 23724172]

23. Kazemi S, Tavakkoli H, Habizadeh MR, Emami MH. Diagnostic values of Helicobacter pylori diagnostic tests: stool antigen test, urea breath test, rapid urease test, serology and histology. J Res Med Sci. 2011;16(9):1097-104. [PubMed: 22973378]

24. Vaira D, Malfertheiner P, Megraud F, Axon AT, Deltenre M, Gasbarrini G, et al. Noninvasive antigen-based assay for assessing Helicobacter pylori eradication: a European multicenter study. The European Helicobacter pylori HpSA Study Group. Am J Gastroenterol. 2000;95(4):925-9. doi: 10.1111/j.1572-0241.2000.01931.x. [PubMed:10763939]

25. Sarkeshikian SS, Iranikhah A, Ghadir MR. Azithromycin based triple therapy versus standard clarithromycin based triple therapy in eradication of Helicobacter pylori infection in Iran: a randomized controlled clinical trial. Turk J Gastroenterol. 2013;24(1):10-4. [PubMed: 23794338]

26. Sullivan B, Coyle W, Nemec R, Dunteman T. Comparison of azithromycin and clarithromycin in triple therapy regimens for the eradication of Helicobacter pylori. Am J Gastroenterol. 2002;97(10):2536-9. doi: 10.1111/j.1572-0241.2002.06036.x. [PubMed: 12385435]

27. Bahremand S, Zamani A, Foroutan H, Tirgari F, Nooripour S, Razavi L, et al. EVALUATION OF TRIPLE AND QUADRUPLE REGIMENS IN ERADICATION OF HELICOBACTER PYLORI INFECTION IN PEDIATRIC PATIENTS IN EMAM KHOMEINI HOSPITAL IN 20022003: A RANDOMIZED CLINICAL TRIAL. Med J Islam Republic Iran .2005;19(1):29-33.

28. Kato S, Takeyama J, Ebina K, Naganuma H. Omeprazole-based dual and triple regimens for Helicobacter pylori eradication in children. Pediatrics. 1997;100(1):e2360. [PubMed: 9200377]
29. Mosleh MN, Gharibi M, Alikhani MY, Saidijam M, Vakhshiteh F. Antimicrobial susceptibility and analysis of macrolide resistance genes in Streptococcus pneumoniae isolated in Hamadan. Iran J Basic Med Sci. 2014;17(8):595-9. [PubMed: 25422753]

30. Shahcheraghi F, Nakhost Lotfi M, Nikbin VS, Shooraj F, Azizian R, Parzadeh M, et al. The First Macrolide-Resistant Bordetella pertussis Strains Isolated From Iranian Patients.JundishapurJ Microbiol. 2014;7(6):e2360. doi:10.5812/jjm.10880. [PubMed: 25371806]

31. Mohammadi M, Doroud D, Mohajerani N, Massarrat S. Helicobacter pylori antibiotic resistance in Iran. World J Gastroenterol. 2005;11(38):6009-13. [PubMed: 16273615]

32. Milani M, Ghotaslou R, Akhi MT, Nahaei MR, Hasani A, Somi MH, et al. The status of antimicrobial resistance of Helicobacter pylori in Eastern Azerbaijan, Iran: comparative study according to demographics.J Infect Chemother. 2012;18(6):848-52. doi:10.1007| s10156-012-0425-4. [PubMed: 22581031]

33. Khademi F, Poursina F, Hosseini E, Akbari M, Safaei HG. Helicobacter pylori in Iran: A systematic review on the antibiotic resistance. Iran J Basic Med Sci. 2015;18(1):2-7. [PubMed: 25810869]

34. Falsafi T, Sotoudeh N, Feizabadi MM, Mahjoub F. Analysis of Genomic Diversity among Helicobacter pylori Strains Isolated from Iranian Children by Pulsed Field Gel Electrophoresis. Iran JPediatr. 2014;24(6):703-9. [PubMed: 26019775]

35. Chuah SK, Tsay FW, Hsu PI, Wu DC. A new look at anti-Helicobacter pylori therapy. World J Gastroenterol. 2011;17(35):3971-5. doi: 10.3748/wjg.v17.i35.3971. [PubMed: 22046084]

36. Montague S, O'Morain CA. Novel therapeutic approaches to the management of Helicobacter pylori infection. Ital J Gastroenterol Hepatol. 1998;30 Suppl 3:S334-8. [PubMed: 10077769]

37. Rafeey M, Ghotaslou R, Milani M, Farokhi N, Ghojazadeh M. Association between Helicobacter pylori, cagA, and vacA Status and Clinical Presentation in Iranian Children. Iran J Pediatr. 2013;23(5):551-6. [PubMed: 24800016]

38. Minakari M, Davarpanah Jazi AH, Shavakhi A, Moghareabed N, Fatahi F. A randomized controlled trial: efficacy and safety of azithromycin, ofloxacin, bismuth, and omeprazole compared with amoxicillin, clarithromycin, bismuth, and omeprazole as second-line therapy in patients with Helicobacter pylori infection. Helicobacter. 2010;15(2):154-9. doi: 10.1111/j.15235378.2009.00739.x. [PubMed: 20402818] 